\title{
Estimation of Productivity and Efficiency of Cotton Farmers: A Case Study of District Dera Ghazi Khan
}

\begin{abstract}
Abdul Hameed ${ }^{1}$, Ihtsham ul Haq Padda ${ }^{2}$, Abdul Salam ${ }^{3}$
Abstract

This study estimates total technical (TEcrs), pure technical (TEvrs), allocative (AE), and economic (EE) efficiencies of cotton growers in the district Dera Gazi Khan using data envelopment analysis (DEA) technique. The study finds 0.67, 0.94, 0.57, 0.54 and 0.71 average values of the total technical, pure technical, allocative, economic, and scale efficiencies, respectively. The study also tries to investigate the determinants of technical inefficiency of cotton growers and the slacks of inputs. The results indicate that human capital, research and development, and easy access to markets are major determinants of technical efficiency. The output orientation analysis shows that production of cotton can be increased by 6 maunds (240kgs) per acre under present availability of resources. The slack estimates show that 43 percent cost of inputs is used extra and on average Rs.11, 833 per acre can be saved in this account without loss of output ${ }^{4}$. This study suggests that government should make a strategy to improve irrigation system and provide trainings for optimal utilization of inputs, and ban agro-shops that do not have licenses.
\end{abstract}

Keywords: Technical efficiency, allocative efficiency, economic efficiency, DEA, cotton

\section{Introduction}

Agriculture is a key sector in Pakistan; its share in Gross Domestic Product (GDP) is 21.4 percent with absorption of 45 percent of labor force. Population residing in rural areas of the country, which is almost 60 percent of total population directly or indirectly depends on this sector. The major crops include wheat, cotton, rice, and sugarcane, contributing 25.3 percent to the entire agricultural sector. Cotton is an important cash crop, accounting about $28 \%$ of the value added by major crops (GOP, 2014).

In developing countries, the major part of the population consists on remote areas and faces extreme poverty. Pakistan is one of those countries where a large chunk of the population is linked with the agriculture sector. Cotton is a cash crop that provides

1 Federal Urdu University of Arts, Science and Technology and Innovative Development Strategies (Pvt.) Ltd, hameedleghari@gmail.com

2 Federal Urdu University of Arts, Science and Technology, Islamabad, ihtsham91@yahoo.com

3 Federal Urdu University of Arts, Science and Technology, Islamabad, drsalam46@gmail.com

4 These estimates are in nominal prices of 2012 with respect to the on average cost of inputs per acre multiplied by 43 percent extra cost of inputs. 
money to farmers for reduction in poverty and improvement in living standard in rural areas. Pakistan's economy relies extensively on cotton crop as it has extensive forward and backward linkages in the economy. Cotton production supports textile sector of Pakistan which is the biggest exporting sector.

This study is based on the field survey data of cotton farmers in Dera Ghazi Khan district. Dera Ghazi Khan is an important cotton growing district in southern Punjab. Dera Ghazi Khan as the rest of the province has seen several ups and downs in cotton production in the recent past, impacting on the economy of cotton related sectors, rural poverty and well-being of growers.

Based on the field level input-output data, the study has estimated and examined technical $\left(\mathrm{TE}_{\mathrm{crs}}\right)$ pure technical $\left(\mathrm{TE}_{\mathrm{vrs}}\right)$, actual $(\mathrm{AE})$ and economic $(\mathrm{EE})$ efficiencies of cotton farming in Dera Ghazi Khan District. The study has also analyzed the determinants of technical efficiency and problems and constraints confronting the farmers in their farming in general and cotton production in particular. The efficiency indices as estimated from field data shed light on the extent of technical and allocative inefficiencies obtaining in cotton production at the farm level. These are helpful in ascertaining the potential to improve cotton production without changing the user level of inputs.

Farm practices and other aspects of efficient farmers as observed from the data can be helpful in formulating policy recommendations, extension strategies and other

Table 1: Cotton Production of District Dera Ghazi Khan

\begin{tabular}{|c|c|}
\hline Years & Production in '000' Bales \\
\hline $2005-06$ & 515 \\
\hline $2006-07$ & 519 \\
\hline $2007-08$ & 464 \\
\hline $2008-09$ & 233 \\
\hline $2009-10$ & 356 \\
\hline $2010-11$ & 212 \\
\hline $2011-12$ & 344 \\
\hline
\end{tabular}

Source: Directorate of Agriculture, Crop Reporting Service, Punjab (2012)

development programs to increase cotton production.

Table 1 presents the production of the cotton production of district Dera Ghazi Khan. Dera Ghazi Khan district is an important cotton growing area. However, cotton production in the district has experienced several ups and downs in the last few years and so impacting the economy and well-being of the population of the district. There 
is potential to improve output without changing the inputs. Farm and farming characteristics of efficient farmers will be used to formulate policy recommendations and to develop strategies for enhancing farm efficiency. This will be important in extension work The study also analyzes the determinants of technical efficiency. Furthermore, the study helps in understanding the core problems which are being faced by cotton farmers in district Dera Ghazi Khan.

The remaining study has been structured as: Section 2 explains literature review. Section 3 consists of sampling and experimental models. Section 4 is devoted for empirical estimation and the last section illustrates the conclusions and presents policy implications.

\section{Literature Review}

Literature review of this research study is divided into two segments which is according to the research protocol.

\subsection{Theoretical Literature Review}

Productivity and efficiency convey different meanings. Productivity is an absolute concept which measures output to input ratio, while efficiency measures the comparison of real production to optimal production ratio (Farrell, 1957). It provides the multi-combination of inputs and outputs related to the production frontier. These functions are divided into two categories. One is output distance functions and the other is input distance function. Output distance function is the maximum relative extension of output vector with respect to input (Banker, Charnes, \& Cooper, 1984) while the input distance function is regarded as a minimum relative contraction input vector with respect to the output.

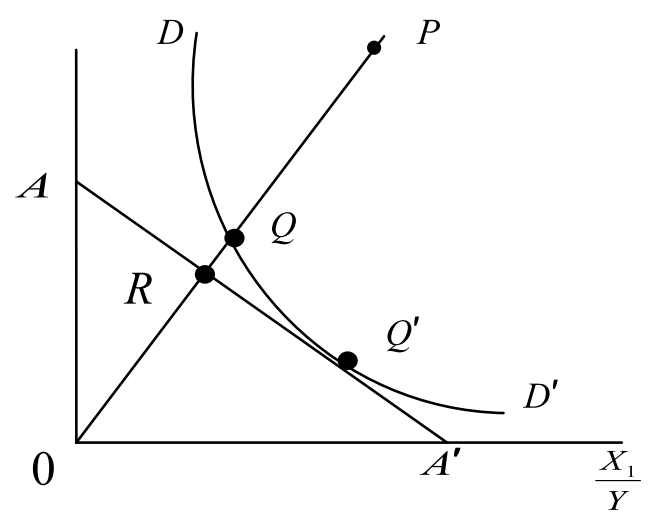

Figure 1: Input Oriented Measures 
Farrell (1957) explains the concept of input and output based measures. This study also follows these efficiency measures. For example firm (A) uses different inputs that can produce one output $Y$ with the assumption of constant returns-to-scale (CRS). In Figure $1 \mathrm{DD}^{\prime}$ represents the iso-quant curve and $\mathrm{AA}$ ' represents the iso-cost line. For example, the firm (A) uses combination of inputs and produces output at point $\mathrm{P}$ which is technically inefficient point because at point $\mathrm{P}$ technical efficiency is less

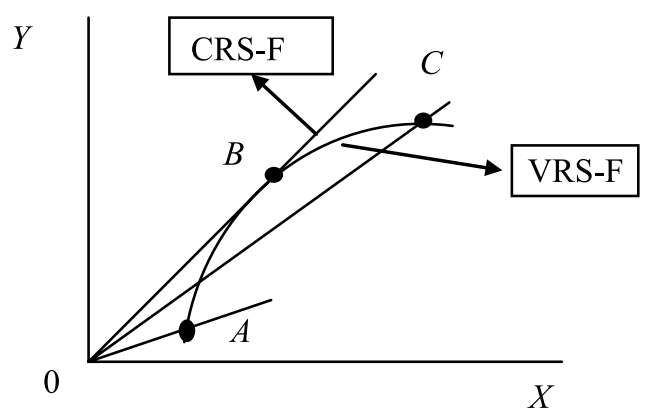

Figure 2: Scale Efficiency Measure

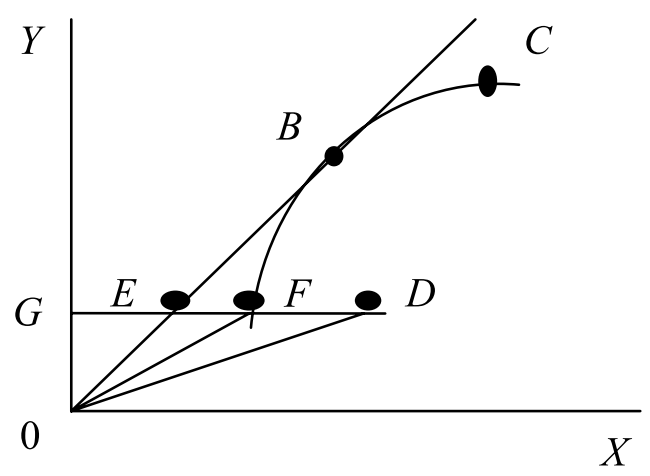

Figure 3: Understanding Scale Efficiency

than 1 and distance QP could be reduced without changing the production level.

Based on above figures: following equations present the method of calculation of different types of efficiencies.

$$
\mathrm{TE}=\frac{\mathrm{OQ}}{\mathrm{OP}}
$$

Where TE is Technical Efficiency

$$
\mathrm{CE}=\frac{\mathrm{OR}}{\mathrm{OP}}
$$

Where CE is Cost Efficiency 


$$
\mathrm{AE}=\frac{\mathrm{CE}}{\mathrm{TE}}
$$

Where AE is Allocative Efficiency

$$
\mathrm{AE}=\frac{\mathrm{OR}}{\mathrm{OP}} * \frac{\mathrm{OP}}{\mathrm{OQ}}=\frac{\mathrm{OR}}{\mathrm{OQ}}
$$

This paper uses a Data Envelopment Analysis (DEA) technique with constant returns to scale and variable returns to scale to estimate the technical, allocative, and economic efficiencies. Figure 2 shows one input and one output production function where VRS-F production function is concave and CRS-F is a 45 degree production function with positive slope. All three farmers $\mathrm{A}, \mathrm{B}$ and $\mathrm{C}$ are not equally productive by scale efficiency effect. Farmer A is working at IRS because the slope is increasing at an increasing rate and move towards the point $\mathrm{B}$. It is a point where constant-returns-to scale tangent to the production frontier. Figure 2 is modified into Figure 3, where farmer $\mathrm{D}$ is operating at inefficient level and where productivity is improved by moving farmer $\mathrm{D}$ to the point where farmer $\mathrm{E}$ exists and further improvement can be made by moving toward point $\mathrm{B}$, where slope $\underline{\mathrm{OD}}$ is equal to ratio $\mathrm{GE}$, and

is equal to $\frac{\mathrm{GE}}{\mathrm{GF}}$.

$\overline{\mathrm{OE}} \overline{\mathrm{GD}}$

$$
\begin{aligned}
& \text { TEVRS }=\frac{G F}{G D} \\
& \text { TECRS }=\frac{G E}{G D}
\end{aligned}
$$

It can be used to calculate the scale efficiency as

Where SE is Scale Efficiency

$$
S E=T E_{c r s} / T E_{v r s}=\frac{G E}{G D} \times \frac{G D}{G F}=\frac{G E}{G F}
$$

\subsection{Empirical Literature Review}

A number of studies are available in the literature that present technical efficiency of cotton and other agriculture crops Watto and Muqera (2014) estimate efficiency of cotton growers in Pakistan through trans-log production function. Results indicate technical inefficiency of cotton farmer's decrease through the educational reforms and extension services. Adzawla, Fuseini and Donkoh (2013) estimated technical efficiency of cotton production in Yendi Municipality, Northern Ghana. Study results revealed that individual farm-level technical efficiency mean value is 0.88 . The study suggested that in order to gain the complete benefits of commercializing cotton production in the region, both farmers and the cotton companies should engage in agreement. Saddozai, Saboor, Azeem and Dawood (2013) analyzed the effect of farmer school education on technical efficiency. The result showed that on average, technical efficiency score was 0.77 which implies that there is a significant gap to improve the 
output and technical efficiency. The Tobit outcomes indicate that respondent age and education level are positively related to cotton yield and negatively related to the inefficiency score.

Sohail, Latif, Abbsa, and Shahid (2012) estimated the technical efficiency for wheat crop of district Sargodha. The study used DEA methodology for calculation of efficiencies and Tobit regression was used for estimation of the factors of efficiency. Results showed that efficiency varied from 0.6 to 1 . While the farm size and village distance are negatively related to technical efficiency. A similar study using DEA by Javed et al. (2009) shows average TE, AE, and EE are $0.87 \%, 0.44 \%$, and $0.37 \%$, respectively. It also indicated that farmers' education and Agriculture-extension services are negatively related to the inefficiency of cotton and wheat farming.

Gul, Koc, Akbinar and Parlakay (2009) estimated the determinants of technical efficiency of cotton growing farms in Turkey. Average technical efficiency was found 0.79. Gwandi, Bala, and Danbaki (2010) estimated the efficiency of cotton growers in Taraba State of Nigeria. The stochastic frontier analysis (SFA) used to conclude TE, $\mathrm{AE}$ and EE efficiencies. Results showed that $82 \%$ of output of cotton is described by input factors. The results also showed that resources are over-utilized therefore farmers need more knowledge on input use.

Sylvain, Nqassam, Joseph, and Cletus (2010) also used the SFA to assess the TE of cotton growers in Cameroon. Results indicated that technical efficiency indices vary from 11 percent to 91 percent. Ogunniyi and Oladejo (2011) estimated the TE of tomato growers in Oyo State of Nigeria. They used DEA methodology to examine the TE and Tobit analysis for the factors of inefficiency. Results showed that average technical and scale efficiencies are 0.42 and 0.82 , respectively. Study argued that education and experience are major factors of technical efficiency. Abid et al. (2011) using Cobb-Douglas production function estimates the TE of BT cotton growers. The results show that BT cotton production has IRS. In previous studies, descriptive statistics analysis was used to describe socioeconomic characteristics of cotton farmers while the DEA and SFA were commonly used to analyze the productivity and efficiencies.

Literature review revealed that most of the studies used DEA, SFA, and Tobit for the assessment of TE, AE, EE efficiencies and source of technical inefficiency. The above cited literature has helped in formation of the design for present study. This study will be first that present literature regarding cotton output orientation analysis and slack estimation in district Dera Ghazi Khan. 


\section{Methodology}

\subsection{Sample Size and Sampling Design}

District Dera Ghazi Khan was selected for the study as not much information in cotton farming and related aspects is available as few researchers go to such for flung areas for socioeconomic studies. It consists of 41 union councils. The 7 out of 41 union councils were dropped due to urban or absence of cotton crop.

First Stage: 8 union councils were randomly selected from 33 union councils as primary sampling units (PSU's).

Second Stage: 15 farmers were randomly selected as secondary sampling units (SSU's) from each of 8 PSU's on the basis of different categories such as small, medium and large farmers. Hence a total of 120 farmers were interviewed as part of this study. In the long history of Pakistan population growth, increased in migration, increased in urban areas, and depreciation in the rupee has mainly contributed in the last few decades to increase the demand for residential housing and decrease the vegetation area (Qidwai \& Hussian, 2012).

Due to all the aforementioned factors, the holding land pattern has changed over time. After the pilot survey in district Dera Ghazi Khan it was proved that mostly large landowners are shifting their preferences from agriculture to other businesses. Owing to these reasons the State Bank of Pakistan (SBP) restructured the definitions of large, medium, and small farmers which are as under:

1. Category (A): Small farm, having 1 to 3 acres of cultivated area under cotton crop

2. Category (B): Medium farm, having 3 to 6 acres of cultivated area under cotton crop

3. Category $(C)$ : Large farmers, having more than 6 acres of cultivated area under cotton crop

There are a few limitations in present survey questions. In district Dera Ghazi Khan, most of the farmers are less or uneducated and do not account the inputs and outputs records. Therefore, errors and inconsistencies are still expected.

\subsection{Empirical Models}

The non-parametric linear programming, Data Envelopment Analysis (DEA) is used as an empirical model. It takes the following form:

Objective: $\operatorname{Min}_{\theta},{ }_{\lambda} \theta$ 
Subject to:

$$
\begin{gathered}
-\mathrm{y}_{\mathrm{i}}+\mathrm{Y} \lambda \geq 0 \\
\lambda \geq 0
\end{gathered}
$$

Where:

$\theta$ : technical efficiency of ith cotton farmer

Y: output matrix for $\mathrm{N}$ cotton farmers

$\lambda:$ Nx1 constant

$\mathrm{X}$ : input matrix for $\mathrm{N}$ cotton farmers

$Y_{i:}$ per acre cotton output in kilograms of the ith cotton farmer

$X_{\mathrm{i}}$ : inputs vector of $\mathrm{X}_{1 \mathrm{i}}, \mathrm{X}_{2 \mathrm{i}} \ldots \mathrm{X}_{8 \mathrm{i}}$

$\mathrm{X}_{1: \text { : }}$ crop area in acres of the ith cotton farmer

$\mathrm{X}_{2 \mathrm{i}}$ total quantity of seed per acre in kilograms used by the ith cotton farmer

$\mathrm{X}_{3 i}$ total quantity of nitrogen per acre in kilograms used by the ith cotton farmer

$\mathrm{X}_{4 \mathrm{i}}$ total quantity of phosphate per acre in kilogram used by the ith cotton farmer

$\mathrm{X}_{5 \mathrm{i}}$ : total tractor hours of operations utilized by the ith cotton farmer (used in land preparation, weeding, planting, etc.)

$\mathrm{X}_{6 \mathrm{i}}$ total quantity of pesticides per acre in liters used by the $i$ th cotton farmer

$\mathrm{X}_{7 \mathrm{i}}$ total number of irrigation per acre in hours used by the ith cotton farmer

$\mathrm{X}_{8 \mathrm{i}}$ : total labor (family and hired) as the total number of man-days ${ }^{5}$ utilized by the ith cotton farmer.

To estimate the pure technical efficiency, DEA model is used which is shown as under, with the assumption of VRS (Coelli et al., 2005). $\operatorname{Min}_{\theta},{ }_{\lambda} \theta$

Objective

Subject to $-y_{i}+Y \lambda \geq 0$

$$
\theta x i-\chi \lambda \geq 0
$$


$N 1^{\prime} \lambda=1$

$\lambda \geq 0$

Where:

$N 1 \lambda \lambda$ represents convexity constraint which ensures that inefficient farm is only benchmarked against farm of a similar size.

This paper also uses DEA cost minimization method following Coelli et al. (2005) with the assumption of VRS for estimation of cost efficiency:

Objective $\quad \operatorname{Min}_{\lambda^{\prime} x_{i}}{ }^{E}$ wixi $^{E}$

$$
-y_{i}+Y \lambda \geq 0
$$

Subject to

$$
\begin{aligned}
& x i^{E}-X \lambda \geq 0 \\
& N 1^{\prime} \lambda=1 \\
& \lambda \geq 0
\end{aligned}
$$

Where:

$\mathrm{W}_{\mathrm{i}}$ : vector of input price $\mathrm{w}_{1 \mathrm{i}}, \mathrm{w}_{2 \mathrm{i}}, \mathrm{w}_{3 \mathrm{i}} \ldots \mathrm{w}_{12 \mathrm{i}}$ of the ith cotton farmer,

$x i^{E}$ : cost minimizing vector of input quantizes for the ith cotton farmer,

$\mathrm{N}$ : total number of cotton farmers in the sample,

$\mathrm{W}_{1 \mathrm{i}}$ : per acre land cost in rupees for the ith cotton farmer

$\mathrm{W}_{2 \mathrm{i}}$ : total cost of seed per acre in rupees used by the ith cotton farmer

$\mathrm{W}_{3 \mathrm{i}}$ : total cost of nitrogen per acre in rupees used by the ith cotton farmer

$\mathrm{W}_{4 \mathrm{i}}$ total cost of phosphate per acre in rupees used by the ith cotton farmer

$\mathrm{W}_{5 \mathrm{i}}$ : total cost of tractor hours of operations utilized by the ith cotton farmer (used in land preparation, weeding, planting, etc.)

$\mathrm{W}_{6 \mathrm{i}}$ : total cost of pesticides per acre in rupees used by the ith cotton farmer

$\mathrm{W}_{7 \mathrm{i}}$ : total cost of irrigation per acre in rupees used by the $i$ th cotton farmer

$\mathrm{W}_{8 \mathrm{i}}$ : total cost of labor (family and hired) as the total number of man-days utilized by the ith cotton farmer 
Cost efficiency is the ratio between the minimum possible cost and the observed cost.

$$
\mathrm{CE}=\frac{w i x{ }^{E}}{w i x i}
$$

Allocative efficiency is estimated by dividing the cost efficiency over the technical efficiency.

$$
\mathrm{AE}=\frac{\mathrm{CE}}{\mathrm{TE}}
$$

Scale efficiency is estimated by dividing the technical efficiency of CRS over the technical efficiency of VRS.

$$
S E=\frac{T E_{C R S}}{T E_{V R S}}
$$

Scale efficiency score varies from zero to one. Score equaling one indicates efficiency and less than one indicates inefficiency. $\mathrm{TE}_{\mathrm{crs}}, \mathrm{TE}_{\mathrm{vrs}}, \mathrm{AE}, \mathrm{EE}$, and SE efficiency scores are estimated using computer software DEAP 2.1.

\subsection{Determinants of Technical inefficiency}

In the first step, $\mathrm{TE}_{\mathrm{vrs}}$ efficiency scores of cotton growers were estimated through DEA technique. In the second step, technical inefficiency scores of cotton growers were calculated by subtracting the $\mathrm{TE}_{\mathrm{vrs}}$ efficiency score from 1 , which afterwards was used to regress as the dependent variable on socioeconomic and farmer's specific factor to assess the sources of inefficiency.

The same approach is adopted in this study in order to classify sources of technical inefficiency by using Tobit regression model.

Where:

$$
\begin{aligned}
& E_{i}=\beta_{0}+\beta_{1} Z_{1}+\beta_{2} Z_{2}+\beta_{3} Z_{3}+\beta_{4} Z_{4}+\beta_{5} Z_{5}+\mu_{i} \\
& \text { If } \quad E^{*}>0, \quad E=0
\end{aligned}
$$

$i$ : ith cotton farmers in sample,

$E_{i}$ : technical efficiency of the ith cotton farmer

$Z_{1}$ : education in years of schooling of the ith cotton farmer

$Z_{2}$ : farming experience in years of the ith cotton farmer

$Z_{3}:$ farm size in acres of the $i$ th cotton farmer

$Z_{4}$ : access to extension services for the ith cotton farmer in the cotton season, 
$Z_{5}$ : distance in kilometers of the ith cotton farmer from main market

$\beta$ 's: unknown parameters to be estimated,

$\mu_{i}$ : is the error term.

\section{Results and Discussions}

Basic statistics of of key variables used in Data Envelopment Analysis (DEA) are presented in Table A1 (appendix). The table presents per acre input quantities and per acre ${ }^{6}$ cost. These results are calculated from 119 sampled units, while one unit was dropped as an outlier. $\mathrm{TE}_{\mathrm{crs}}, \mathrm{TE}_{\mathrm{vrs}}, \mathrm{AE}, \mathrm{EE}$, and SE efficiencies are presented in Table A2 (appendix) and Table 2. Table 2 shows 0.67 mean of total technical efficiency of sampled farmers, which varies from 0.21 to 1.0. The results indicate that if cotton growers operate at an optimal level, then on average their inputs can be reduced by 33 percent to produce the same level of output. The average $\mathrm{TE}_{\mathrm{vrs}}$ of sampled farmers is 0.94 , which varies from 0.64 to 1.0 . The average $\mathrm{AE}$ of sampled farmers is 0.57 , which varies from 0.18 to 1.00 . The joint effect of $\mathrm{TE}$ and $\mathrm{AE}$ efficiencies illustrations that average $\mathrm{EE}$ is 0.54 , with a minimum of 0.17 and maximum of 1.00 .

Table 2: Total Technical (TEcrs), Pure Technical (TEvrs), Allocative (AE), Economic (EE) and Scale (SE) Efficiencies

\begin{tabular}{|c|c|c|c|c|c|}
\hline Efficiencies & TEcrs & TEvrs & AE & EE & SE \\
\hline Mean & 0.67 & 0.94 & 0.57 & 0.54 & 0.71 \\
\hline Minimum & 0.21 & 0.64 & 0.18 & 0.17 & 0.26 \\
\hline Maximum & 1.00 & 1.00 & 1.00 & 1.00 & 1.00 \\
\hline
\end{tabular}

Results indicate that cotton farmers are not optimally technically efficient. Therefore, if the farmers function at optimum level of production they can reduce $46 \%$ cost of production without changing the level of output and present technology. This is because their economic efficiency is 54 percent, while the allocative efficiency shows that there is considerable room available to enhance the productivity of sampled farmers as 43 percent cost of inputs are used in the wrong direction can be improved. Frequency distribution of $\mathrm{TE}_{\mathrm{crs}}, \mathrm{TE}_{\mathrm{vrs}}, \mathrm{AE}$, and $\mathrm{EE}$ efficiencies of farmers are given in Figures 2 to 6 and in Table-A1 (appendix). Figure 4 shows that total $\mathrm{TE}_{\mathrm{crs}}$ of the sampled farmers vary from 0.21 to 1.00 . Most of the farmers' (63\% out of 119$) \mathrm{TE}_{\text {crs }}$ is less than 0.80 while only $23 \%$ have more than 0.90 . The situation seems different in the case of $\mathrm{TE}_{\mathrm{vrs}}$ in the Figure 5, where almost $90 \%$ farmers have $\mathrm{TE}_{\mathrm{vrs}}$ more than 0.90. The pattern of AE and EE are alike (Figure 6 and Figure 7) with both average efficiencies around 0.55 . Like other efficiencies, the farmers are not scaling efficient too (Figure 8).

6 Acre: one acre is equal to 0.04046 hector. 


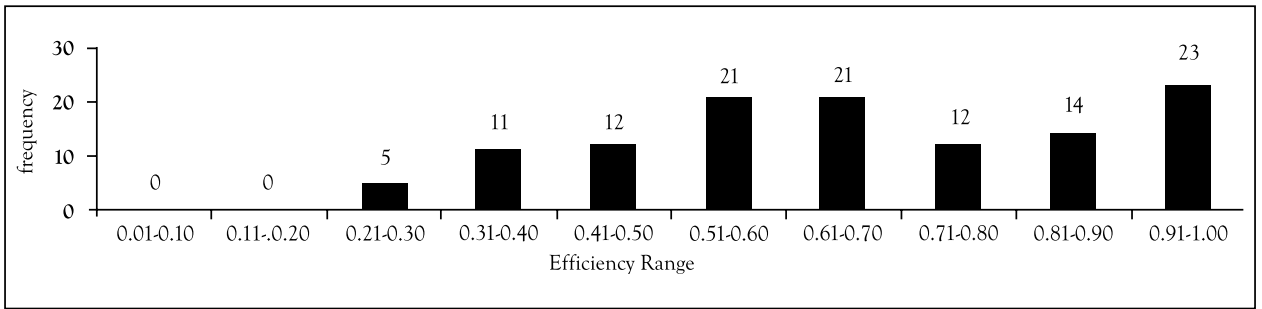

Figure 4: Frequency Distribution of TEcrs Efficiency

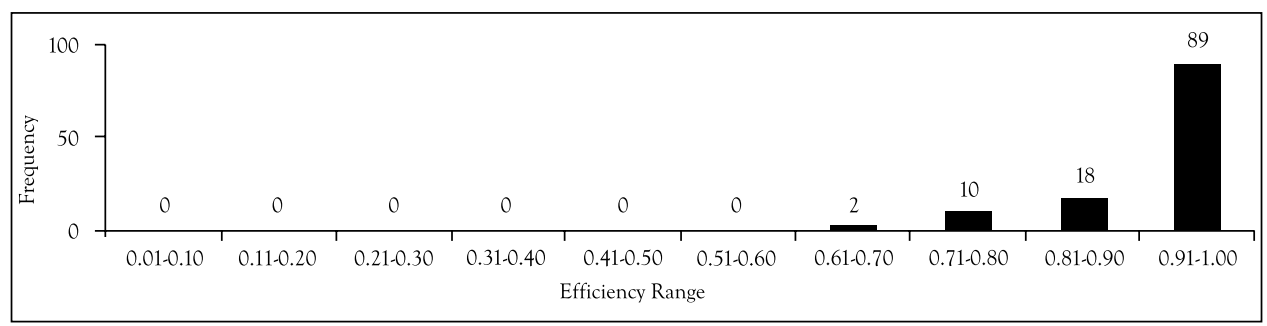

Figure 5: Frequency Distribution of TEvrs Efficiency

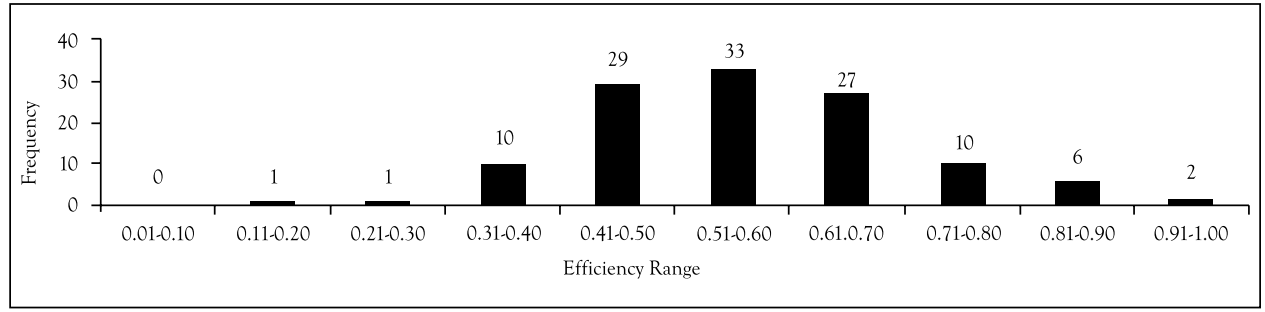

Figure 6: Frequency Distribution of AE Efficiency

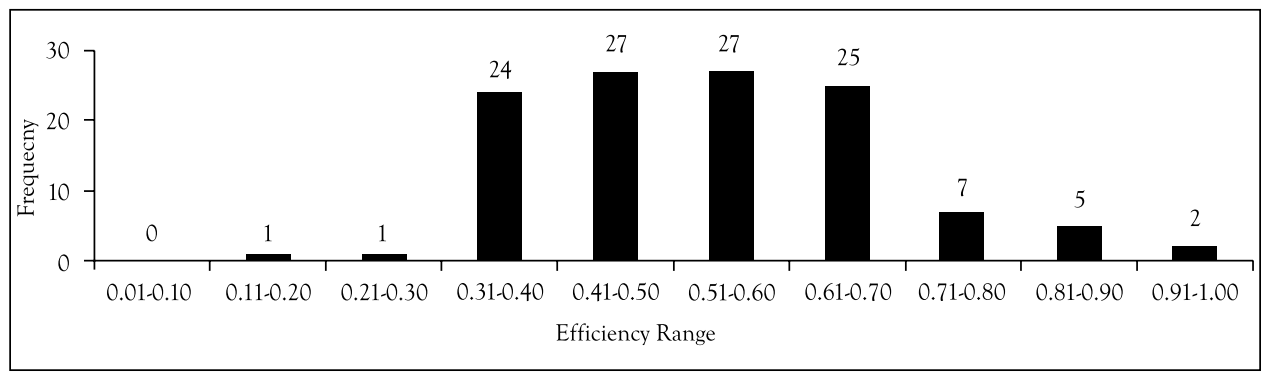

Figure 7: Frequency Distribution of EE Efficiecy

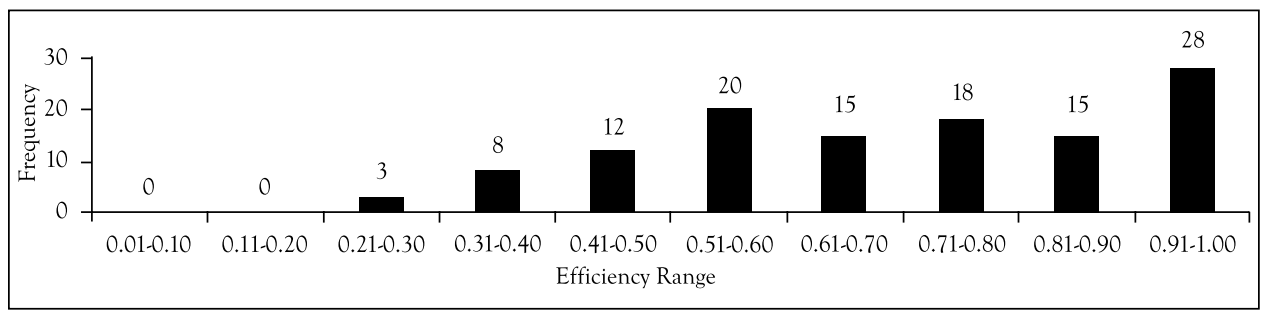

Figure 8: Frequency Distribution of SE Efficiency 


\subsection{Input Slacks Analysis}

It is evident from Table 3 that farmers can reduce cost of inputs by decreasing number of slacks without reducing the output. Slacks are observed in irrigation $(15 \%)$, pesticides $(8 \%)$, nitrogen $(6 \%)$ and labor $(9 \%)$. This is because farmers adopt traditional practices in using the inputs. Therefore, it is important to bring awareness about new technologies and give farmers the training to improve the use of inputs.

Table 3: Input Slacks and Number of Farmer Using Excess Inputs

\begin{tabular}{|c|c|c|c|c|}
\hline Inputs & $\begin{array}{c}\text { Number of } \\
\text { Farmers }\end{array}$ & Mean Slack & $\begin{array}{c}\text { Mean Input } \\
\text { Use }\end{array}$ & $\begin{array}{c}\text { Excess Input } \\
\text { Use (\%) }\end{array}$ \\
\hline Cotton crop land (acres) & 13 & 0.70 & 6.91 & 10.09 \\
\hline Seed per acre ( $\mathrm{kg})$ & 15 & 0.15 & 5.96 & 2.58 \\
\hline Nitrogen (per acre in kg) & 26 & 3.51 & 55.37 & 6.34 \\
\hline Phosphate (per acre in kg) & 16 & 0.47 & 20.94 & 2.23 \\
\hline Tractor (per acre hours) & 19 & 0.09 & 8.67 & 1.07 \\
\hline Pesticides (per acre lt) & 28 & 0.64 & 8.31 & 7.72 \\
\hline $\begin{array}{c}\text { Irrigation (no. per acre in } \\
\text { hours) }\end{array}$ & 34 & 1.92 & 13.15 & 14.59 \\
\hline $\begin{array}{c}\text { Labor days (per acre man- } \\
\text { days) }\end{array}$ & 28 & 1.68 & 19.53 & 8.58 \\
\hline
\end{tabular}

\subsection{Relationship between Efficiency Estimates and Cropping Area}

In order to investigate the relationship between efficiencies and crop area, the cultivated crop area was categorized into three groups on the basis of operational land holdings of farmers. Farm size (A) consists of 1 up to 3 acres of cultivated area under cotton crop and categorized as small farm, farm size (B) consists of 3 up to 6 acres area cultivated under cotton crop and categorized as a medium farm, and farm size (C) consists of 6 and above acres area cultivated under cotton crop and categorized as a large farm. The $\mathrm{TE}_{\mathrm{crs}}, \mathrm{TE}_{\mathrm{vr}}, \mathrm{AE}, \mathrm{EE}$, and $\mathrm{SE}$ efficiencies scores, comparative to the farm size in the cotton crop are reported in Table-4. The $\mathrm{TE}_{\text {crs }}, \mathrm{TE}_{\mathrm{vrs}}, \mathrm{AE}, \mathrm{EE}$, and SE of small farm size sampled farmers are $0.72,0.96,0.55,0.53$ and 0.75 , respectively. The medium farm size sampled farmers have The $\mathrm{TE}_{\mathrm{crs}}, \mathrm{TE}_{\mathrm{vrs}}, \mathrm{AE}, \mathrm{EE}$, and SE efficiencies as $0.65,0.93,0.61,0.57$ and 0.69 , respectively. The large farm size sampled farmers have The $\mathrm{TE}_{\mathrm{crs}}, \mathrm{TE}_{\mathrm{vrs}}, \mathrm{AE}, \mathrm{EE}$, and $\mathrm{SE}$ efficiencies as $0.62,0.92,0.55,0.51$ and 0.67 , respectively.

In the total technical, allocative, economic and scale efficiencies among cropping categories, category (A) farmers are more efficient than category (B) and (C) farmers, 
Table 4: Means of Total Technical (TECRS), Pure Technical (TEVRS), Allocative, Economic and Scale Efficiencies Estimates according To Farm Size in Cotton crop

\begin{tabular}{|c|c|c|c|c|c|}
\hline Categories & TEcrs & TEvrs & AE & EE & SE \\
\hline $\begin{array}{c}\text { A (1 up to 3 } \\
\text { acres) }\end{array}$ & 0.72 & 0.96 & 0.55 & 0.53 & 0.75 \\
\hline $\begin{array}{c}\text { B (3 up to 6 } \\
\text { acres }\end{array}$ & 0.65 & 0.93 & 0.61 & 0.57 & 0.69 \\
\hline $\begin{array}{c}\text { C (6 and } \\
\text { above acres) }\end{array}$ & 0.62 & 0.92 & 0.55 & 0.51 & 0.67 \\
\hline
\end{tabular}

category (B) farmers are more efficient than category (C) farmers. The smallest category of farmers is more efficient because they are mostly relying on family labors and seem to be working quite diligently with lot of care and proper management and making efficient use of inputs and lands.

Table 5: Means of Total Technical (TECRS), Pure Technical (TEVRS), Allocative, Economic and Scale Efficiencies Estimates according To Farm Size in Cotton crop

\begin{tabular}{|c|c|c|c|}
\hline Categories & CRS & IRS & DRS \\
\hline A ( 1 up to 3 acres $)$ & $20 \%$ & $80 \%$ & - \\
\hline B (3 up to 6 acres $)$ & $15 \%$ & $83 \%$ & $2 \%$ \\
\hline C ( 6 and above acres $)$ & $10 \%$ & $90 \%$ & - \\
\hline
\end{tabular}

As presented in Table 4 and Table 5 , scale efficiency of category (A) is 0.75 . The 20 percent sampled farmers are on a constant returns-to-scale (CRS) while remaining are on increasing returns-to-scale (IRS). It indicates that 80 percent of sampled farmers need to increase operational scale to enhance the productivity and efficiency. Medium farmers (category-B) have a scale efficiency of 0.69. Among them only 15 percent are on a constant returns-to-scale (CRS) and remaining 83 percent are on increasing returns-to-scale (IRS). The large farmers (category-C) have scale efficiency of 0.67. Only 10 percent of sampled farmers are on a constant returns-to-scale (CRS) and 90 percent are on increasing returns-to-scale (IRS). These results show that in all categories most of the farmers are on increasing returns-to-scale (IRS), i.e. they can increase their output by changing their operational scale. It will also enhance their efficiencies.

\subsection{Estimates of Target Output in Cotton Crop}

This study also presents target output estimates based on output orientation methodology. This technique has an advantage of estimating the maximum possible production. Table-6 gives the summary of target output. Target refers to the amount of output the decision-making units (DMU) should aim at producing given the available 
unit of inputs and technology. The minimum output target that some of the DMUs should aim at producing the target output is 6.8 maunds per acre. The maximum output target range is 36 maunds per acre.

Table 6: Frequency Distribution of Output Target in Cotton System (

\begin{tabular}{|c|c|c|}
\hline Range & Frequency & Percentage \\
\hline $1.00-5.00$ & 0 & 0.00 \\
\hline $6.00-10.00$ & 13 & 10.9 \\
\hline $11.00-15.00$ & 12 & 10.1 \\
\hline $16.00-20.00$ & 35 & 29.4 \\
\hline $21.00-25.00$ & 14 & 11.8 \\
\hline $26.00-30.00$ & 17 & 14.3 \\
\hline$>30$ & 28 & 23.5 \\
\hline Total & 119 & 100.0 \\
\hline
\end{tabular}

The average actual production is 16.46 maunds per acre, but according to output orientation analysis, the sampled farmers can produce on average 22.5 maunds per acre without reducing or increasing their current level of inputs and technology. As per the data provided in Table 6 , there is tremendous scope for the increasing cotton production in the sample farmers. The expected increase per acre ranges from 6 to 30 maunds of seed cotton.

\subsection{Analysis of Determinants of Technical Inefficiency}

The socioeconomic factors are expected to affect the level of technical efficiency of farmers. This study also makes an attempt to find out the sources of technical inefficiency and external factors of the cotton crop in District Dera Ghazi Khan. The Tobit regression analysis is used to estimate the determinants of technical inefficiency and external factors. Table 7 shows that the coefficients of human capital (education, experience, and contact with extension agents) are significantly negative consistent with our prior expectations. This implies that educated farmers are technically less inefficient than cotton farmers with less or no schooling. These results are similar to Sohail et al. (2012), Gul et al. (2009) and Ali and Flinn (1989) who argue that the educated farmers have better access to information, technology and standard inputs. Moreover, they can have effective dealing with financial issues. Similarly for experience is also negatively and significantly related to technical inefficiency. These results are similar to Bravo-Uretta (1994), Sohail, et al. (2012), Ali and Flinn (1989) and Abid et al. (2011). This indicates that farmers' experience has an important effect on productivity and technical efficiency of cotton farming. Experienced farmer can manage 
the farming uncertainty and production techniques in a better way. The coefficient of research and development, as measured by contact with extension agents has a negative and significant effect on the technical inefficiency of cotton farmers. It implies that farmers have more information about the approved agricultural inputs are less technical inefficient than those are not familiar with the new inputinformation. Results of this study are in the line with results of Javed et al. (2009), i.e. when farmers contact with extension agents, they get more information about modern farming, weather condition, cropping preparation, information about seeds, fertilizers and other requirements.

Table 7: Determinants of Technical Inefficiency of Cotton System with Tobit Analysis

\begin{tabular}{|c|c|c|c|}
\hline Variables & Coefficient & Std. Error & p-value \\
\hline Constant & $0.439^{* * *}$ & 0.081 & 0.00 \\
\hline Education & $-0.019^{*}$ & 0.010 & 0.066 \\
\hline Experience & $-0.003^{*}$ & 0.002 & 0.081 \\
\hline Extension Workers & $-0.008^{*}$ & 0.006 & 0.083 \\
\hline Farm Size & $0.002^{*}$ & 0.001 & 0.079 \\
\hline Market Distance & $0.020^{* *}$ & 0.009 & 0.025 \\
\hline
\end{tabular}

Note: ${ }^{* * *}$ significant at 0.01 level. ${ }^{* *}$ significant at 0.05 level. ${ }^{*}$ significant at 0.10 level

Cotton farm size is positively and significantly related to the technical inefficiency of the cotton crop. This implies that large farm size is technically more inefficient than small farm size. However, on the basis of technology available to farmers of Dera Gazi Khan, bigger farm size can be a cause of low efficiency as proper management would not be easy. Most farmers use private Muzarey (labor) which are also illiterate and have financial constraints due to which they cannot properly manage the large unit. These situations create many problems for productivity and efficiency. The distance from form to the main market of agriculture inputs and output is positively associated with technical inefficiency. According to (FAO, 2004), the purchase of inputs is high in a developing country if the supply of inputs is available at the walking distance. Roads and market infrastructures are highly related to agriculture production because outputs properly reach in the market at proper time and at less damage caused by extreme weathers.

\section{Conclusions and Policy Implications}

The present study is designed to estimate technical, pure technical, allocative and economic efficiencies and to investigate the determinants of technical efficiency of cotton farmers in district Dera Ghazi Khan. The data were collected for the crop year 2012 from 120 respondents. Data Envelopment Analysis (DEA) technique was 
used to estimate the technical, allocative and economic efficiencies and the Tobit regression analysis was used to estimate the determinants of technical efficiency. Result derived from DEA model indicated that mean total technical, pure technical, allocative, economic and scale efficiencies were $0.67,0.94,0.57,0.54$ and 0.71 , respectively. Findings also uncovered that if farmers could manage optimal levels of inputs, they can reduce 33 percent inputs and 46 percent cost without changing the level of output and technology because the technical and allocative efficiencies are 67 percent and 54 percent, respectively. Results showed that category-A (small) farmers are more technical, allocative and economically efficient than category-B (medium) and category-C (large) farmers The results of target output analysis showed that sampled farmers can produce, on average, 22.5 maunds per acre of seed cotton same level of inputs and technology, while the actual output was 16.46 maunds per acre. The results of Tobit regression showed that education, experience, extension workers have significant negative relationship with technical inefficiency, while farm size and market distance were found to have positive relationship with technical inefficiency of the cotton crop.

Based on the findings of the study reported above some implications are in order: to increasing efficiency and productivity of cotton farming. The study shows that farmers having more contact with extension agents are less inefficient than farmers having low contacts with such agents. This situation can be improved and resources save through aggressive extension campaigns and apprising the farmers about the timely and rational use of various inputs and technologies. The distance of form from market also matters. Therefore, road and market infrastructure needs to be improved. One of the important results of this study is that 15 percent irrigation water wasted and needs to be saved through all means and efforts. The government should improve irrigation system. Moreover, land leveling can also improve irrigation efficiency.

\section{References}

Abid, M., Ashfaq, M., Quddus, A., Tahir, A., \& Fatima, N. (2011). A resource use efficiency analysis of small bt cotton farmers in Punjab, Pakistan. Pakistan Journal of Agriculture, 48(1), 75-81.

Adzawla, W., Fuseini, J., \& Donkoh, S. A. (2013). Estimating technical efficiency of cotton production in Yendi Municipality, Northern Ghana. Journal of Agriculture and Sustainability, 4(1), 115-140.

Ali, M., \& Flinn, J. (1989). Profit efficiency in basmati rice producers in Pakistan's Punjab. American Journal Of Agricultural Economics, 71, 303-310.

Banker, R.D., Charnes, A., \& Cooper, W.W. (1984). Some models for estimating technical efficiency and scale inefficiencies in Data Envelopment Analysis. Management Science, 30, 1078-1092.

Bravo-Uretta, B. E., \& Evenson, R. E. (1994). Efficiency in agricultural production: The case of peasant 
farmers in eastern Paraguay. Journal of Agricultural Economics, 10, 27-37.

Coelli, T. (1996). A guide to DEAP version 2.1. A data envelopment analysis (computer) program. Australian Journal of Agricultural Economic, 39, 219-245.

Coelli, T., Rao, D., \& Battese, G. (2005). An Introduction to Efficiency and Productivity Analysis. Springer.

Dlamini, S., Rugambisa, I., Masuku.B.M, \& Belete.A. (2010). Technical efficiency of the small scale sugarcane farmers in Swaziland: A case study of Vuvulane and big bend farmers. African Journal of Agriculture Research, 5(9), 935-940.

Ebong, V., Okoro, U., \& Effiong, E. (2009). Determinants of technical efficiency of urban farming in Uyo Metropolis of Akwa Ibom State, Nigeria. Journal of Agriculture and Social Science, 5, 89-92.

FAO. (2004). Fertilizer use by crop in Pakistan, land and plant nutrition management service, land and water development division, FAO, Rome.

Farrell, M. (1957). The measurement of productivity efficiency. Journal of The Royal Statistics Society, Series A, 120, 253-290.

GOP. (2014). Economic Survey of Pakistan. Ministry of Finance, Govt of Pakistan.

Gul, M., Koc, B., Akbinar, G., \& Parlakay, O. (2009). Determination of technical efficiency in cotton growing farms in Turkey: A case study of Oukurova region. African Journal of Agriculture Research, 4(10), 944-949.

Gwandi, O., Bala, M., \& Danbaki, J. (2010). Resource use efficiency in cotton production in Gassol local government area of Taraba State, Nigeria. Journal of Agriculture and Social Science, 87-90.

Hajian.Mohammadhadi, S. (2013). Total factor productivity and efficiency in Iranian crop. Research Journal of Agricultural and Environmental Management, 2(2), 033-043.

Javed, I., Adil, A., Hassan, S., \& Ali, A. (2009). An efficiency of punjab cotton-wheat system. The Lahore Journal of Economics, 2(14), 97-124.

Khurram Nawaz Saddozai, A. S. (2013). Analyzing the impact of farmer field school on technical efficiency of cotton growers in southern districts of Punjab Pakistan: Stochastic production frontier approach. Sarhad Journal of Agriculture, 29(2).

Qidwai, M. Y., \& Hussian M., (2012). Pakistan real estate market. Karachi: Colliers International Pakistan (Pvt.) Ltd.

Ogunniyi, L., \& Oladejo, J. (2011). Technical efficiency of tomato production in Oyo State Nigeria. Agricultural Science Research, 1(4), 84-91.

Sohail, N., Latif, K., Abbsa, N., \& Shahid, M. (2012). Estimation of technical efficiency and investigation of efficiency variables in wheat production: A case of district Sargodha (Pakistan). Interdisciplinary Journal of Contemporary Research in Business, 3(10), 897-904. 
Sylvain, B., Nqassam, C., Joseph, N., \& Cletus, N. (2010). The determinants of the technical efficiency of cotton farmers in northern cameroon. MPRA, 24814, 50-62.

Tobin, J. (1995). Estimation of relationship for limited dependent variable. Econometrica, 26, 24-36.

Watto, M. A., \& Muqera, A. (2014). Measuring efficiency of cotton cultivation in Pakistan: A restricted production frontier study. Journal of the Science of Food and Agriculture, 3038-45.

\section{Appendices}

Table A1: Determinants of Technical Inefficiency of Cotton System with Tobit

Analysis

\begin{tabular}{|c|c|c|c|c|}
\hline Variables & Minimum & Maximum & Mean & Std. Deviation \\
\hline $\begin{array}{l}\text { Output per acre } \\
\text { in } \mathrm{kg}\end{array}$ & 240.0 & 1440.0 & 657.10 & 223.0153 \\
\hline $\begin{array}{c}\text { Total farm land } \\
\text { in acres }\end{array}$ & 1.0 & 200.0 & 10.40 & 19.3541 \\
\hline $\begin{array}{l}\text { Land under cot- } \\
\text { ton crop in acres }\end{array}$ & 1.0 & 40.0 & 6.91 & 6.9563 \\
\hline $\begin{array}{c}\text { Seed per acre } \\
\text { in } \mathrm{kg}\end{array}$ & 3.8 & 10.0 & 5.96 & 1.6712 \\
\hline $\begin{array}{l}\text { Nitrogen per acre } \\
\text { in } \mathrm{kg}^{7} \\
\end{array}$ & 9.0 & 147.0 & 55.37 & 23.4862 \\
\hline $\begin{array}{c}\text { Phosphate per } \\
\text { acre in } \mathrm{kg}\end{array}$ & 4.6 & 69.0 & 20.94 & 7.5348 \\
\hline $\begin{array}{c}\text { Per acre tractor } \\
\text { hours }\end{array}$ & 4.0 & 14.0 & 8.67 & 1.5490 \\
\hline $\begin{array}{l}\text { Pesticides per acre } \\
\text { in litre } \\
\end{array}$ & 1.5 & 18.1 & 8.31 & 3.1337 \\
\hline $\begin{array}{l}\text { No. of Irrigation } \\
\text { per acre in hours }\end{array}$ & 4.0 & 32.0 & 13.15 & 7.3619 \\
\hline $\begin{array}{l}\text { Labor days per } \\
\text { acre man-days }\end{array}$ & 4.5 & 57.0 & 19.53 & 11.2650 \\
\hline $\begin{array}{c}\text { Per acre land cost } \\
\text { in Rs }\end{array}$ & 5000.0 & 20000.0 & 10263.03 & 2259.1758 \\
\hline $\begin{array}{c}\text { Per acre seed cost } \\
\text { in Rs }\end{array}$ & 400.0 & 3000.0 & 1437.60 & 574.3237 \\
\hline $\begin{array}{l}\text { Per acre nitrogen } \\
\text { cost in Rs }\end{array}$ & 684.8 & 11184.8 & 4220.16 & 1792.6342 \\
\hline
\end{tabular}

7 Nitrogen $\mathcal{E}$ phosphate amount estimate from ratio of nitrogen in $50 \mathrm{~kg} \mathrm{bag}$ 


\begin{tabular}{|c|c|c|c|c|}
\hline $\begin{array}{c}\text { Per acre phos- } \\
\text { phate cost in Rs }\end{array}$ & 727.0 & 9945.7 & 3052.40 & 1093.8497 \\
\hline $\begin{array}{c}\text { Per acre tractor } \\
\text { hours cost in Rs }\end{array}$ & 1200.0 & 4800.0 & 2825.63 & 664.3738 \\
\hline $\begin{array}{c}\text { Per acre pesticide } \\
\text { cost in Rs }\end{array}$ & 2200.0 & 13000.0 & 7058.10 & 2058.3371 \\
\hline $\begin{array}{c}\text { Per acre irrigation } \\
\text { cost in Rs }\end{array}$ & 910.0 & 10533.3 & 3067.01 & 1621.5261 \\
\hline $\begin{array}{c}\text { Per acre labor } \\
\text { cost in Rs }\end{array}$ & 1350.0 & 17100.0 & 5858.15 & 3379.7743 \\
\hline
\end{tabular}

Source: Field Survey by Author, 2012

Table A2: Efficiencies of Sample Farmers of District Dera Ghazi Khan

\begin{tabular}{|c|c|c|c|c|c|c|c|c|c|c|}
\hline \multirow{2}{*}{$\begin{array}{c}\text { EFFICIEN- } \\
\text { CY RANGE }\end{array}$} & \multicolumn{2}{|c|}{ TECRS } & \multicolumn{2}{c|}{ TEVRS } & \multicolumn{2}{c|}{ AE } & \multicolumn{2}{c|}{ EE } & \multicolumn{2}{c|}{ SE } \\
\cline { 2 - 12 } & Freq & $\%$ & Freq & $\%$ & Freq & $\%$ & Freq & $\%$ & Freq & $\%$ \\
\hline $0.01-0.10$ & 0 & 0.0 & 0 & 0.0 & 0 & 0.0 & 0 & 0.0 & 0 & 0.0 \\
\hline $0.11-0.20$ & 0 & 0.0 & 0 & 0.0 & 1 & 0.8 & 1 & 0.8 & 0 & 0.0 \\
\hline $0.21-0.30$ & 5 & 4.2 & 0 & 0.0 & 1 & 0.8 & 1 & 0.8 & 3 & 2.5 \\
\hline $0.31-0.40$ & 11 & 9.2 & 0 & 0.0 & 10 & 8.4 & 24 & 20.2 & 8 & 6.7 \\
\hline $0.41-0.50$ & 12 & 10.1 & 0 & 0.0 & 29 & 24.4 & 27 & 22.7 & 12 & 10.1 \\
\hline $0.51-0.60$ & 21 & 17.6 & 0 & 0.0 & 33 & 27.7 & 27 & 22.7 & 20 & 16.8 \\
\hline $0.61-0.70$ & 21 & 17.6 & 2 & 1.7 & 27 & 22.7 & 25 & 21.0 & 15 & 12.6 \\
\hline $0.71-0.80$ & 12 & 10.1 & 10 & 8.4 & 10 & 8.4 & 7 & 5.9 & 18 & 15.1 \\
\hline $0.81-0.90$ & 14 & 11.8 & 18 & 15.1 & 6 & 5.0 & 5 & 4.2 & 15 & 12.6 \\
\hline $0.91-1.00$ & 23 & 19.3 & 89 & 74.8 & 2 & 1.7 & 2 & 1.7 & 28 & 23.5 \\
\hline TOTAL & 119 & 100 & 119 & 100 & 119 & 100 & 119 & 100 & 119 & 100 \\
\hline
\end{tabular}

